Research Article

\title{
Evaluation of pharmacology teaching-learning methods in a government medical college
}

\author{
Aritra Ghosh*, Krishnendu Mandal, Suvadip Biswas, Saikat Kumar Dalui, Mithilesh Haldar, \\ Supreeti Biswas
}

\begin{abstract}
Department of Pharmacology, Burdwan Medical College, Burdwan, West Bengal, India
\end{abstract}

Received: 2 November 2015 Accepted: 17 December 2015

*Correspondence to:

Dr. Aritra Ghosh,

Email: draritraghosh@gmail.com

Copyright: (C) the author(s), publisher and licensee Medip Academy. This is an open-access article distributed under the terms of the Creative Commons Attribution Non-Commercial License, which permits unrestricted non-commercial use, distribution, and reproduction in any medium, provided the original work is properly cited.

\begin{abstract}
Background: Pharmacology is a major subject in medical science and always changing, so according to it pharmacologists also need to reform their teaching method. Students' opinion in this evaluation of teaching is a good option.

Methods: A questionnaire based study was conducted in Burdwan Medical College on 230 students of two batches.

Results: One forty eight students thought that the subject was interesting. Twenty eight percent students opined that Pharmacology class was not interesting. Students found interest mostly in prescription writing, drug interaction and therapeutic problems in practical section. Though $53.4 \%$ found pharmacy was less interest. They suggested some reforms in teaching, $61.3 \%$ voted for introduction of audio-visual aid and $74.3 \%$ response on clinical demonstration in hospital ward. According to $82.6 \%$ students, there should be more problem solving exercise during teaching pharmacology; giving hand-out before everyday class, class in clinical setting and more emphasis on clinical pharmacology were also needed. MCQ exam only (31\%) and written viva both $(51 \%)$ were good ways of evaluation according to them.

Conclusions: This study helps in knowing students' opinion and preferences in curriculum to make it more interesting and aids to modify the undergraduate Pharmacology teaching pattern.
\end{abstract}

Keywords: Questionnaire, Teaching, Practical, Pharmacy

\section{INTRODUCTION}

Pharmacology is the pillar of medicine and deals with drugs and therapeutics. Without it there will be no new drug discovery and treatment will become at halt. The main objective of teaching Pharmacology is to understand drugs and enable medical students to take right therapeutic decisions in their future medical practice. However, this objective is neglected and not emphasised by the prevailing curriculum. ${ }^{1}$ In West Bengal, teaching in pharmacology takes place by didactic lecture class, practical class, demonstration class and group discussion. In the practical part, students are taught pharmacy, prescription writing, clinical problems etc. Learning pharmacology to choose and prescribe drugs is a major challenge encountered by students. ${ }^{2}$ It is a major role of clinical pharmacologists to teach students but no need to say that this teaching methodology needs a good change in approach. In 1969, the World Health Organisation (WHO) convened a study group on clinical pharmacology in order to point out the scope and use of this discipline. They concluded that the tasks of the clinical pharmacologist include: (1) research into the action of drugs in humans, (2) services such as providing information on drugs and (3) teaching clinical pharmacology and therapeutics (CP\&T) to medical students, hospital staff and physicians. ${ }^{3}$ Other two except teaching improved as time passed, though teaching part is the most under developed and given very less importance among them. For this reason, undergraduate students fail to learn the subject and know little about the therapeutic use of drugs after passing MBBS; some doctors actually know very less on the subject and rely solely on the promotional literature and information from the pharmaceutical industry. So to improve teaching and evaluation methods by students' opinion is a good option and widely accepted, also is a very important tool for undergraduate medical teaching. ${ }^{4,5}$ Undergraduate students are the main concern here so they can actually tell pros and cons of teaching and this feedback method to assess the process is a main tool now a days. ${ }^{6}$ Our study aims towards the perception and view of medical students about pharmacology as a subject, evaluation process and their suggestion on teaching and learning pharmacology in future. 


\section{METHODS}

A cross-sectional questionnaire based study was conducted in the department of pharmacology, Burdwan Medical College in West Bengal for one month time period. Fifth semester MBBS batch of 150 students who are going to appear in $2^{\text {nd }}$ professional MBBS examination and $6^{\text {th }}$ semester MBBS batch of 100 students who passed the $2^{\text {nd }}$ professional MBBS examination few months back participated in the study. Written consent for participation in the study was obtained and a pre-tested semi-structured questionnaire administered to them. They were asked to select the options which they felt was/ were the best, allowing them to opt for more than one option where it was mentioned and to give their suggestions in the last part of questionnaire. Participants were instructed not to mention their name or any other identification except the semester in it. The investigators were present in case the respondents required assistance. Data were collected in a pre-structured format. Collected data were entered in Excel sheet and analysed with proper statistical method.

\section{RESULTS}

Among 250 students, 230 consented for the study and agreed to fill in the supplied questionnaire.

Students' gross opinion about pharmacology subject was revealed. One forty eight students $(64.3 \%)$ think that pharmacology is interesting. Sixty six students (28.7\%) think this subject is useful in future but needs lots of cramming. pharmacology subject seems boring and useless cramming to some students (Table 1).

Though $72 \%$ students found classes of pharmacology interesting but also a good number of students (28\%) found those classes boring also (Figure 1).

Figure 2 revealed that in which chapters students found interest during studying. Forty percent students' response were on cardiovascular system, $42.6 \%$ students found central nervous system and autonomic nervous system interesting. Many students (35.6\%) thought that antimicrobials chapter was very good to read and according to $33 \%$ gastrointestinal system was interesting. Responses on general pharmacology, cancer chemotherapy, respiratory system, endocrine system were around $10-20 \%$ (Figure 2).

Two hundred four students $(88.7 \%)$ students opined that pharmacology subject would be very useful in their future medical life whereas others thought that it was of no help.

Eighty two (35.6\%) students opined that lecture classes were most helpful for understanding. Group-discussion seemed helpful to $28.7 \%$ students. Practical classes and demonstration classes helped to understand the subject to around $15 \%$ of students (Table 2 ).
Regarding the practical section of pharmacology, 174 students $(75.6 \%)$ found that practical part was interesting and to $56(24.4 \%)$ students practical part was boring.

On Practical section, 82 students (35.6\%) found prescription writing interesting. Therapeutic problem and drug interaction seemed interesting to 118 students $(51.3 \%)$ and 76 students $(33 \%)$ respectively. On the other side, pharmacy seemed less interesting to $53.4 \%$ students (123 students). $31.7 \%$ students (73) and $24.8 \%$ students (57) opined that chart and dosage form respectively also created less interest in them. At least 42 students opined that pharmacy which was taught is no longer needed in their future medical life, so the class was useless (Figure $3)$.

Students' opinions on reform needed in pharmacology teaching were mostly introduction of audio-visual aid $(61.3 \%)$ and clinical demonstration in hospital ward (74.3\%) (Table 3).

According to $82.6 \%$ of students' view, there should be more problem solving exercise during teaching pharmacology. Some students $(17.4 \%)$ thought that there is no need for that. Majority students $(94.3 \%)$ opined that distribution of hand-out giving outline of day's class should be a very good option and $91.3 \%$ students' opinion was that unless pharmacology was learnt along with clinical conditions, it would be difficult to correlate the drugs with the disease. Ninety percent students thought that clinical pharmacology should be emphasised more by giving more time than theoretical pharmacology.

According to students' opinion most effective evaluation method was written and viva both $(51 \%)$. According to $31 \%$ students MCQ test could be a good alternative, although $15 \%$ of students' opinion was for viva only and very few for written test only (Figure 4).

They prepared the subject by various methods, $38.7 \%$ students prepared the subject from text book only; some students prepared it from class notes, self-prepared notes and internet. Around $20 \%$ followed text books and class notes both, $20 \%$ read the subject from text book, class notes and self-prepared notes and $14.3 \%$ students prepared from all the mentioned sources (Figure 5).

Table 1: Opinion on pharmacology subject $(\mathrm{N}=230)$.

\begin{tabular}{|cc|}
\hline Opinion on pharmacology subject & $\begin{array}{c}\text { Response } \\
\text { No }(\%)\end{array}$ \\
\hline Interesting & $148(64.3)$ \\
\hline Boring & $10(4.3)$ \\
\hline Useful and cramming & $66(28.7)$ \\
\hline Useless and cramming & $6(2.7)$ \\
\hline
\end{tabular}


Table 2: Types of class students found helpful $(\mathrm{N}=\mathbf{2 3 0})$.

\begin{tabular}{|ll|}
\hline Class they found most helpful & $\begin{array}{l}\text { Students' response } \\
\text { no }(\%)\end{array}$ \\
\hline Lecture class & $82(35.6 \%)$ \\
\hline Tutorial class & $20(8.7 \%)$ \\
\hline Practical class & $33(14.3 \%)$ \\
\hline Group discussion & $66(28.7 \%)$ \\
\hline Demonstration class & $29(12.7 \%)$ \\
\hline
\end{tabular}

Table 3: Reforms needed in pharmacology teaching according to students opinion $(\mathrm{N}=\mathbf{2 3 0})$.

\begin{tabular}{|ll|}
\hline $\begin{array}{l}\text { Reforms students need in } \\
\text { pharmacology teaching }\end{array}$ & Response (\%) \\
\hline Decrease lecture class & $56(24.3)$ \\
\hline Increase lecture class & $39(16.9)$ \\
\hline Audio-visual aid & $141(61.3)$ \\
\hline Clinical demonstration in ward & $171(74.3)$ \\
\hline
\end{tabular}

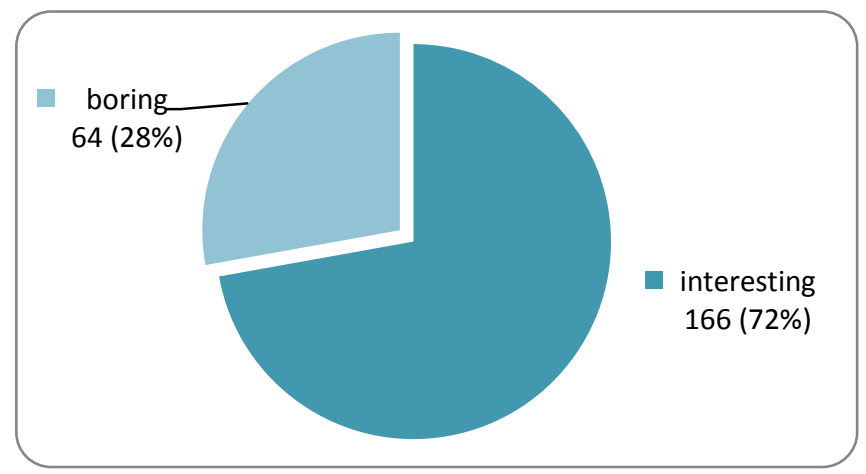

Figure 1: Opinion on pharmacology class $(\mathrm{N}=\mathbf{2 3 0})$.

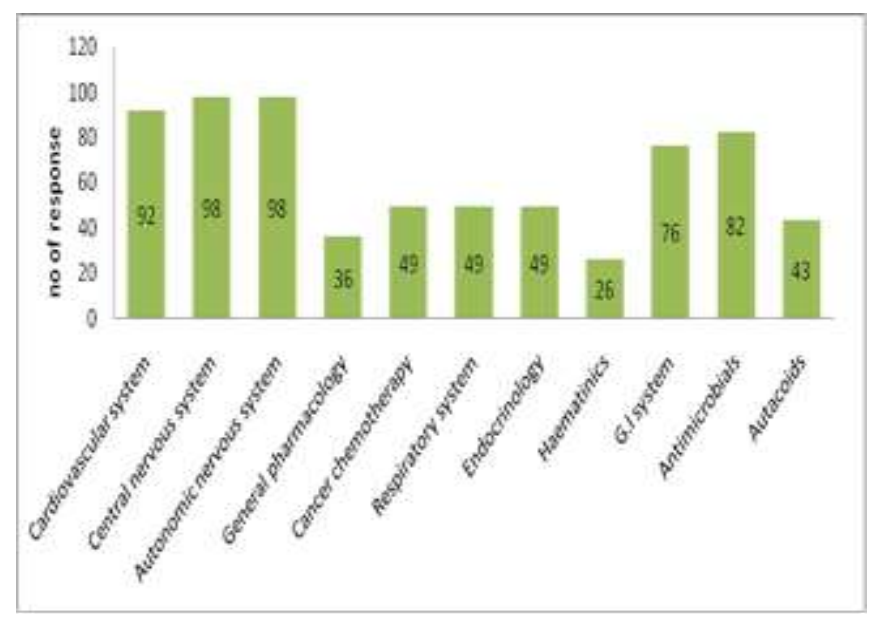

Figure 2: Chapter of pharmacology students found interesting $(\mathrm{N}=\mathbf{2 3 0}$, maximum response possible on single option).

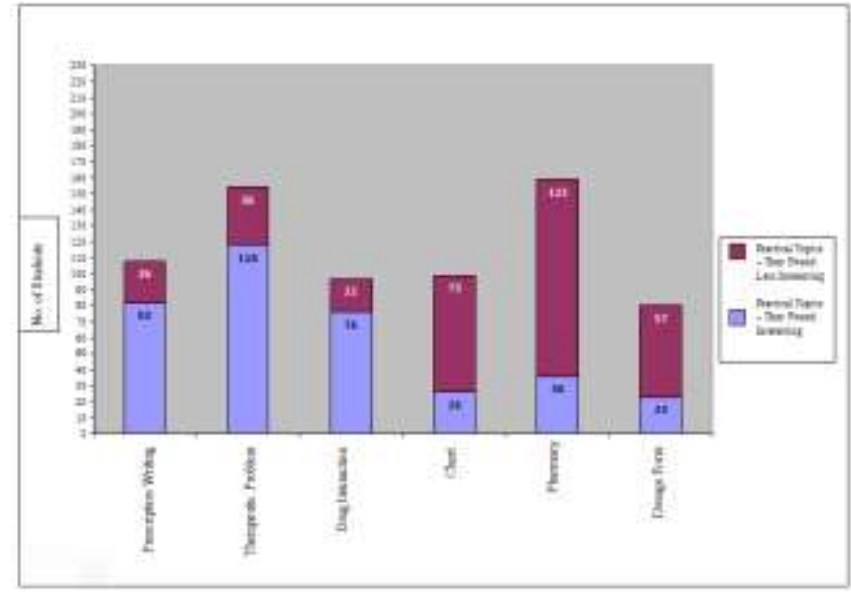

Figure 3: Practical topics students found interesting (in blue) and practical topics students found less interesting (in violet) $\mathrm{N}=\mathbf{2 3 0}$.

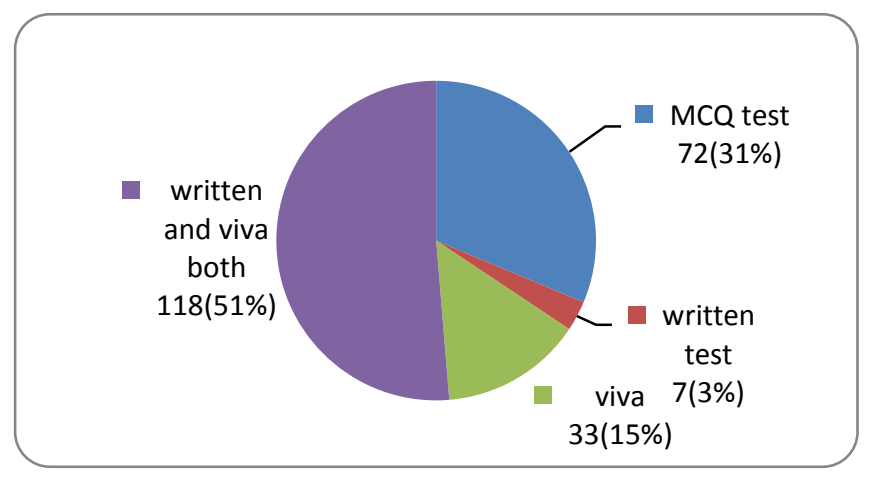

Figure 4: Students' opinion on effective evaluation method for pharmacology $(\mathrm{N}=\mathbf{2 3 0})$.

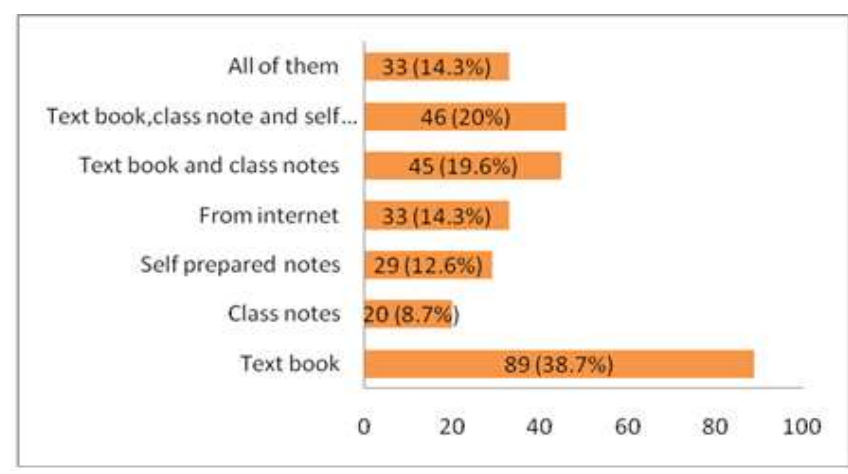

Figure 5: Students' methods for preparing Pharmacology (max response in single option is 230 ).

\section{DISCUSSION}

This evaluation of pharmacology teaching is important because we have to know the pulse of the students, their interest and their opinion on methods of teaching in pharmacology and their perception regarding pharmacology. ${ }^{7}$ This type of student's feedback represents the primary tools used by most programs to assess their methodology. ${ }^{5,6}$ Problem based learning and 
clinics oriented teaching help students to choose and prescribe drugs rationally in their future professional life though in conventional teaching they face very less practical scenario. Clinical pharmacology is concerned with the scientific study of drugs in man. One of the central roles of the clinical pharmacologist is the assessment of new drugs in man. ${ }^{8}$ Though in most of the colleges in West Bengal conventional learning is given priority like in Burdwan Medical College where pharmacology is taught by didactic lecture, tutorial, demonstration class. Main problem of conventional learning is that it separates basic science from clinical segment. Conventional teaching is tutor-centred and mostly one directional. Here teachers take classes and deliver long lectures and students only play a passive role, no active participation in didactic lectures. LCD aided power point lectures are quite common tool for teaching in most of the institutions now. The main drawback here which may be common with the overhead transparencies also i.e. students do not concentrate on the teachers' lecture as they are busy on taking down the notes. Note-taking in lectures interferes with understanding. ${ }^{9}$ For this reason, they sometimes found the subject difficult and lose interest in pharmacology. In this study also $28 \%$ students opined that pharmacology classes were boring. While In a student-centred problembased curriculum, students participate in the class by actively solving problems rather than only taking notes. The problem based learning curriculum uses a problem as the starting point for student learning. ${ }^{10}$ The pharmacology course in China now a days consists of a combination of lectures, problem based learning sessions, clinic-correlated lectures and small group discussions. ${ }^{11}$ In Malaysia, pharmacology learning is of more clinical reasoning, they reform it from laboratory based medicine teaching to more patient oriented approach. ${ }^{12}$ There should be continuous interaction between pharmacologists and clinicians at the level of teaching pharmacology and pharmacology should be taught with clinical teaching. ${ }^{13}$ In our study students' opinion is very valuable. Many students (35.6\%) opined that lecture classes were most helpful but also according to $24.3 \%$ students' opinion decrease in lecture class and increase in audio-visual aid would help much. This institute like many other colleges lacks audio-visual aids, which is very much helpful for students to understand the subject. So in our study students also opined that and $61.3 \%$ students said introduction of audio-visual aid is very much needed in pharmacology teaching. Students cannot correlate the subject with practical settings as the subject is taught only in theoretical way. Students $(91.3 \%)$ also stated that it should be taught with clinical teaching and 90\% students thought that clinical pharmacology should be emphasised more than theoretical pharmacology. This subject is the backbone of medicine so must be taught in hospital ward so that students can understand how to prescribe medicines, their use, misuse, adverse effects before their own eyes. According to many (74.3\%) students in this study, clinical demonstration in ward is a genuine reform needed in teaching pharmacology. Only
$14.3 \%$ thought that practical classes were helpful for studying the subject. It is shockingly less because pharmacy practical was their main concern. $53.4 \%$ students thought that pharmacy was less interesting to them and most of them opined that pharmacy is not necessary in their future medical life and medicines they made like carminative mixture, sulphur drugs etc. in pharmacy were of no use now. Prescription writing and therapeutic problem were interesting according to 35.6 and $51.3 \%$ student. Drug interaction was interesting to $33 \%$ students. So it is clear that students found more interest in those practical parts which are clinics oriented and needed in their future life. Regarding assessment or evaluation method, $72 \%$ voted for MCQ examination only, $15 \%$ for viva and $51 \%$ for viva and written test both. They preferred MCQ exams because it is quick and bias-less method of evaluation, very less voted for viva because it has every chance to be biased. They used text book, class notes and self-prepared notes for preparing the subject. Many of them (38.7\%) preferred text books for preparing the subject because in text book they get everything in one place.

\section{CONCLUSION}

Pharmacology is a major subject in medical science and always changing, so according to it pharmacologists also need to reform their teaching method. Problem based learning and clinical pharmacology is the key to this reform. Pharmacological industry is now a good career prospect for medical professionals so teaching on clinical pharmacology should be given more importance now. All over India many attempts have been taken now to make the subject more interesting and students by giving their valuable opinion in this regard help pharmacologists to make those reforms. This study also helps in knowing students' opinion and preferences in curriculum to make it more interesting and aids to modify the undergraduate pharmacology teaching pattern.

\section{ACKNOWLEDGEMENTS}

The authors wish to extend their sincerest thanks to Dr. Saswati Sarkar, Dr. Subha Shankar Chattopadhyay for their enormous support to carry out the above research work. Sincere thanks are also due to $2^{\text {nd }}$ professional MBBS students and $3^{\text {rd }}$ professional MBBS students for their participation in the study.

Funding: No funding sources Conflict of interest: None declared

Ethical approval: This study was approved by Institutional Ethics Committee

\section{REFERENCES}

1. Vasundara K, Kanchan P, Pundarikaksha HP, Girish $\mathrm{K}$, Prassana S, Jyothi R. An imperative need to change pharmacology curriculum: a pilot survey. Indian J Pharmacol. 2010;42:420. 
2. Sudha J. Graduate training programmes in pharmacology in India. Health Administrator Vol XIX;1:88-91.

3. Maxwell SR, McQueen DS, Ellaway R. eDrug: a dynamic interactive electronic drug formulary for medical students. $\mathrm{Br} \mathbf{J}$ Clin Pharmacol. 2006;62(6):673-81.

4. Jayakaran, Chavda N, Yadav P, Kantharia ND. Intern doctors' feedback on teaching methodology in pharmacology. J Pharmacol Pharmacother. 2010;1:114-6.

5. Victoroff KZ, Hogan S. Students perceptions on effective learning experience in dental school: a qualitative study using a critical intern technique. $\mathrm{J}$ Dental Edu. 2006;70:124-32.

6. Richardson BK. Feedback. Acad Emarg Med. 2004;11:e1-5.

7. Tirumalasetty J, Prakash M, Shankar J. Evaluation of student's Opinion regarding pharmacology teaching in Mamata Medical College. Indian J Appl Res. 2013;3:12.

8. Advani UP, Bhojani KG, Gada VP. VMGMC students view on the prevailing teaching methods in pharmacology and changes recommended. Solapur Med J. 2006;2:1-8.
9. Rao KY. Undergraduate pharmacology: student's view - A Questionnaire Study. J Phys Pharm Adv. 2013;3(2):27-32.

10. Burrows HS, Tamlyn RN. Problem-based learning: an approach to medical education. New York, Springer; 1989.

11. Li WD, Zhang $\mathrm{Y}$, Zhang CL, Zhang XM. Pharmacology teaching and its reform in China. Acta Pharmacological Sin. 2004;25:1233-8.

12. Sim SM. Teaching of pharmacology in University Malaya and the other medical schools in Malaysia: a historical perspective. Acta Pharmacological Sin. 2004;25:1209-19.

13. Ruckmani A. The Role of pharmacologists: present and future (report). Indian J Pharmacol. 2006;38(2):145-6.

Cite this article as: Ghosh $\mathrm{A}$, Mandal $\mathrm{K}$, Biswas S, Dalui SK, Haldar M, Biswas S. Evaluation of pharmacology teaching-learning methods in a government medical college. Int J Basic Clin Pharmacol 2016;5:126-30. 